\title{
LXXXVII. On the emission of electrons by metals under the influence of alpha rays
}

\section{H.A. Bumstead}

To cite this article: H.A. Bumstead (1911) LXXXVII. On the emission of electrons by metals under the influence of alpha rays , Philosophical Magazine Series 6, 22:132, 907-922, DOI: $10.1080 / 14786441208637188$

To link to this article: http://dx.doi.org/10.1080/14786441208637188

曲 Published online: 20 Apr 2009.

Submit your article to this journal $₫$

Џ Article views: 2

Q View related articles $\square$

7 Citing articles: 7 View citing articles ๘ 


\section{$\left[\begin{array}{ll}907 & \end{array}\right]$}

LXXXVIT. On the Emission of Electrons by Metals under the Influence of Alpha Rays. By H. A. Bomstead *.

T $\mathrm{T}$ was observed by Bragg and Kleeman $\dagger$ that when a thin 1 sheet of a metal, such as gold, was interposed in the path of a pencil of $\alpha$-rays, the diminution in range produced was less when the metal sheet was far from the source of rays than when it was near ; in other words, the rays seemed to be "stopped" less by the metal when they were going slowly than when they were moving with greater speed. T. S. Taylor $\ddagger$ made a careful study of the phenomenon and found that this differential effect increased regularly with the atomic weight of the metal. Substances whose atomic weight was much greater than that of air showed the effect very markedly ; substances, such as paper, whose average atomic weight was nearly equal to that of air did not show the effect at all; and when a layer of hydrogen was used instead of a solid obstacle, the effect was reversed. By plotting the ionization curves of the $\alpha$-rays in air and in hydrogen, Taylor showed that there was exactly the same relation between the ionization in the two gases at different parts of the range as between their relative stopping powers. Where the ionization in hydrogen was greater than in air, the hydrogen was more effective in retarding the rays, and vice versi $\hat{a}$; and the numerical ratios for the two effects were equal. These results led naturally to the hypothesis that the energy lost by the $\alpha$-particles in their progress through a gas was mainly, if not wholly, consumed in the production of iuns, and that where the ionization was great (as at the "knee" of the Bragg curve) the a-particles lost energy more rapidly than where the ionization was less. As the knee is more conspicuous in hydrogen than in air the relative stopping effects of these two gases are easily accounted for on this hypothesis.

Shortly afterward, Geiger $\S$ published the results of a repetition of Rutherford's measurements of the velocities of the $\alpha$-particle at different points in its range. The measurements were made under more favourable conditions than were possible at the time of Rutherford's original experiments, and Geiger was able to show that the loss of energy by the particles in passing through a layer of air was at least

* Communicated by the Anthor.

$\dagger$ Phil. Mar. x. p. 318 (1905).

t Amer. Journ. Sci. xxviii. p. 357 (1909); Phil. Mag. xviii. p. 604 (1909).

§ Proc, Roy, Soc. lxxxiii. p. 505 (1910). 


\section{Prof. H. A. Bumstead on Eimission of Electrons}

approximately proportional to the ionization produced in that layer, and was not the same for equal paths in air at different parts of the range as Rutberford had supposed. The large value of the ionization as the $\alpha$-particle approaches the end of its range involves a correspondingly rapid diminution of its energy, and this rapid expenditure of energy in all probability brings the $\alpha$-particle to rest at the end of its range instead of leaving it with a residual velocity after it ceases to ionize, as Rutherford at first supposed.

The continuity of the effects observed by Taylor with hydrogen, air, and various metals of increasing atomic weight made it probable that, in solids as well as gases, the a-particles expend their energy in a process analogous to gaseous ionization, and that this process follows a curve similar to the ionization curre in gases. Just as the curve for air has a less conspicuous knee than the hydrogen curve, so, from the stopping effects, we should expect the "ionization curve" of gold, for example, to show less projection than the air-curve. According to this view all atoms are less effective in retarding swift $\alpha$-rays than slow ones; but heavy atoms are relatively more effective in stopping the swift rays than the light atoms, while they are on more nearly equal terms in their effect upon the slower rars. This view accounts satisfactorily for the results obtained by Taylor.

The following experiments were undertaken to obtain, if possible, some direct evidence of the existence of an ionization process in metals subjected to a-rays, and to see whether it varied with the speed of the rays in a manner analogous to the ionization which the rays produce in gases. It has been known for some years that a source of a-rays, or any solid struck by them, emits slow-moving electrons (called $\delta$-rays by Sir J. J. Thomson who discovered them). If the atoms of solids are ionized by the $\alpha$-rays one would expect that some of the electrons set free in the process from the atoms near the surface would escape from the metal, and that the number escaping would be more or less nearly proportional to the number of atoms ionized. Accordingly, measurements were made of the number of electrons escaping from a thin metal foil when struck by $\alpha$-rays at different points in the range.

In order to avoid possible complications from the effects of $\beta$ - and $\gamma$-rays, polonium was used as the source of $\alpha$-rays. Professor Boltwood kindly separated the polonium from a solution of radio-lead and it was deposited on the end of a copper plug, $4 \mathrm{~mm}$. in diameter. The first preparation was not very strong and it was necessary to use a system of small 
by Metals under the Influence of Alpha Rays. $\quad 909$

Fir. 1.

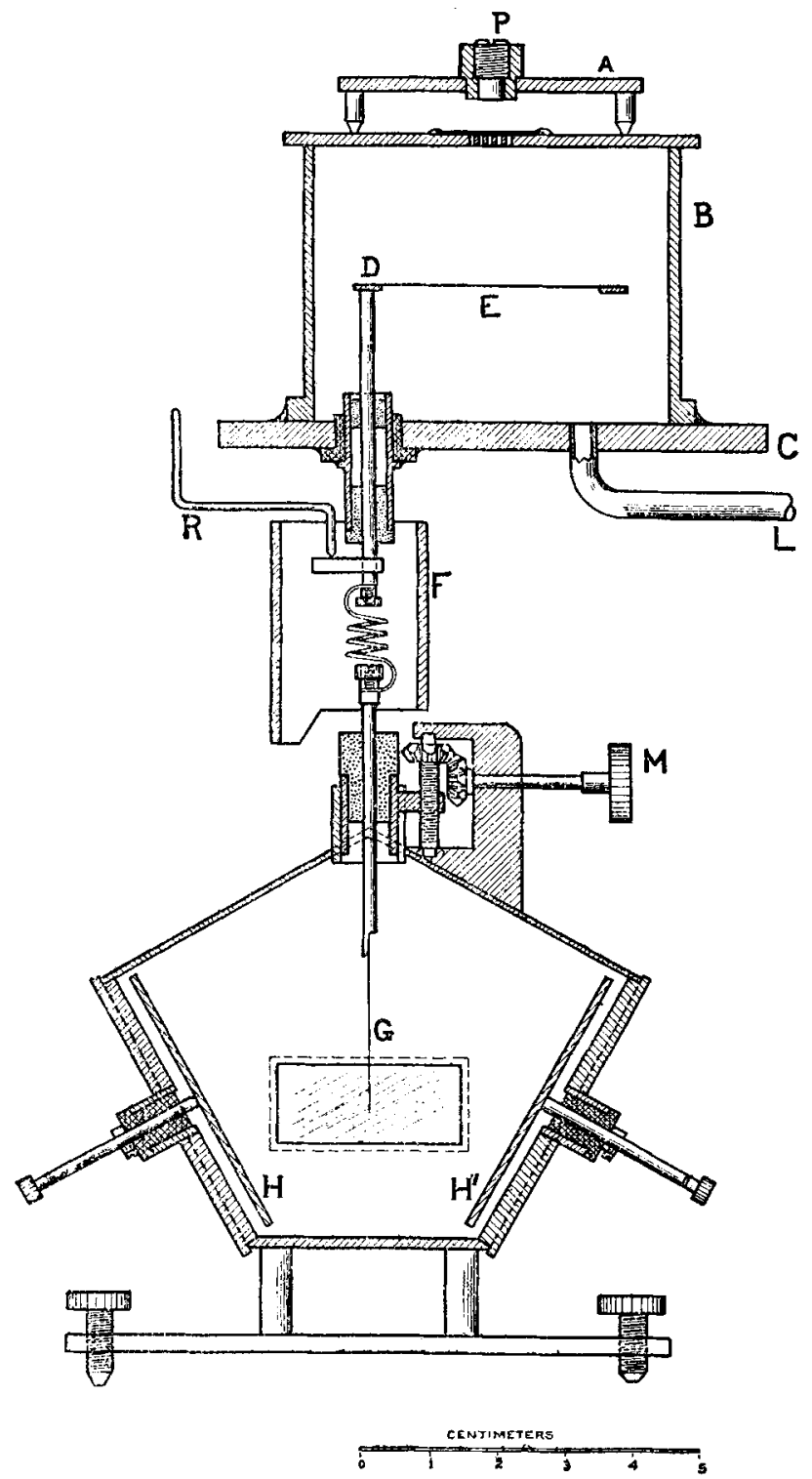

capacity in making the electrical measurements. The following form of apparatus was used (fig. 1).

A piece of thin aluminium leaf $\mathrm{E}, 064 \times 10^{-4} \mathrm{~cm}$. thick, is stretched over the flat brass ring $D$, which has 
a clear opening of $3.2 \mathrm{~cm}$. The brass rod which supports the ring passes through the base-plate $\mathrm{C}$, and is insulated from it by amber, ebonite, and an earthed guard-tube ; the joints are made air-tight with sealing-wax. A cylindrical cover $B$ rests on the base-plate, the two surfaces in contact being ground to each other and made tight with rubber stopcock grease. The interior is connected by means of the tube I. with pump, gauge, and charcoal-bulb. The copper plug $P$, which has the polonium on its lower end, is supported by a little tripod, and there are punch marks in the top of the cover into which the feet of the tripod fit, so that it can be removed and replaced in the same position. The distance from the polonium to the top of the cover is $6 \mathrm{~mm}$. In the cover, just below the polonium, are nine holes, $1 \mathrm{~mm}$. in diameter, to permit the passage of the $\alpha$-rays ; these holes are covered by aluminium foil, $8 \cdot 65 \times 10^{-4} \mathrm{~cm}$. thick. This foil was some that was supplied with tubes intended to demonstrate Lenard rays; it was the thinnest I could find which was not full of boles, and its effect on the range of the a-particles was equivalent to that of $1.47 \mathrm{~cm}$. of air. It was fastened down to the top with a ring of low melting sealingwax, which was then covered with stopcock grease.

The rod which supports the ring and aluminium foil was connected to the gold leaf of an electroscope which had been made some time before in this laboratory. It may be regarded as developed from a Wilson tilted electroscope in the same manner that a twinned crystal is developed from an ordinary one. The two plates $\mathrm{H}$ and $\mathrm{H}^{\prime}$ are charged to equal and opposite potentials (usually 200 volts) as in Hankel's electroscope. The gold leaf is kept in the middle by means of the levelling-screws, and the sensitiveness (and stability) are easily altered by raising or lowering the leaf by means of the milled head $\dot{M}$. The latter adjustment is the chief convenience of this electroscope. The sensitiveness of such an electroscope is a very indefinite thing; it depends upon the degree of instability of zero point and deflexion that one can permit, and this, in turn, depends on the greater or less protection of the case from rapid changes of temperature, currents of air, \&c. This double electroscope appears to have some slight advantage over Wilson's form; when the two were mounted side by side under the same conditions the double electroscope had a sensitiveness about three times that of the tilted form, for equal stability. As used in the present experiments, the capacity of the leaf and its connexions was about $5 \mathrm{~cm}$. and the sensitiveness was so adjusted as to give about 25 or 30 divisions on the scale in the 
microscope for 0.1 volt. The key $R$, which was connected to a potentiometer arrangement, allowed the leaf to be insulated, grounded, or charged to any desired potential, and the volt-sensitiveness was taken immediately after each reading.

The case containing the aluminium foil electrode was exhausted, while the charcoal-bulb was heated, to a pressure of a few thousandths of a millimetre, and the bulb was cooled with liquid air. The bulb was between the case and the pump and thus formed a trap for the mercury vapour. 'Two litres of liquid air were used which lasted for about ten days. For that length of time the air-pressure could be kept continuously below $0001 \mathrm{~mm}$. The pressure of the mercury vapour in the case must have been very small under these conditions. What vapour there was from the rubber stopcock grease used to cover the joint between the baseplate and cover must have been constantly distilling over from the case into the bulb; that its amount was small is shown by the fact that no visible traces of the grease could be seen in the charcoal-bulb after a week or more of this distillation, althongh in the same time drops of mercury of considerable size had distilled over from the pump.

$W^{\prime}$ hen the $\alpha$-rays from the polonium were admitted into the case throngh the aluminium-covered holes in the top, both the insulated electrode and the case emitted electrons under their action. In order to separate the two effects it was necessary to charge the case; when it was charged positively, the electrons which were set free from the case were prevented from reaching the electrode, and the latter received a positive charge due to the loss of electrons from its two surfaces; when the case was charged negatively, the electrode received electrons from the case and emitted nous itself. With +25 volts on the case the current of electrons from the aluminium foil was fully saturated, and it was not increased by the application of +200 volts. With +6 volts the lack of saturation was about 7 per cent. On the other hand, with a negative potential on the case it was distinctly more difficult to reach the saturation value; with -25 volts, the current was 20 per cent. less than with -200 volts. The probable cause for this difference will be discussed in the next paragraph.

When the case was charged negatively, the current was approximately twice as great as when the case was charged positively. Thus, apparently twice as many electrons were emitted by the case under the influence of the $\alpha$-rays as from the two sides of the aluminium-foil electrode through which 


\section{Prof. H. A. Bumstead on Emission of Electrons}

the rays passed. This difference persisted when the case itself was lined with aluminium foil, so it was not due to a specific difference between aluminium and brass. It is probable that the explanation of this difference as well as the difficulty in obtaining negative saturation mentioned in the last paragraph is to be found in the construction of the cover and the apertures through which the rays enter the exhausted chamber. Many of the rays, passing in a divergent pencil throngh the aluminium foil which covers the holes, strike the sides of the holes and do not reach the electrode. They thus liberate a number of electrons from the case and no corresponding ones from the electrode; and to draw all of these superfluous electrons from the small apertures in the top of the cover requires a considerably greater potential-difference than when they come from the electrode.

In order to find out whether the observed currents really had their source in the metals and were not due to residual gas or vanour, the foil was removed from the ring electrode. (The apertures in the top of the cover were so placed that the geometrical beam of rays fell entirely within the ring.) Under these conditions, the current with the case charged positively fell to 4 per cent. of its former value, while with a negative potential on the case the current was 90 per cent. of what it had been before. This slight falling off in the negative current was doubtless due to the fact that the ring electrode was less efficient in catching electrons from the case than when it was covered with foil. Of the small positive current, part at least was due to the rays which struck the brass rod which supported the ring (see fig. 1), so that, we may be quite sure that the gas-effect contributes not more than 2 or 3 per cent. to the currents observed with this apparatus. The absence of positive particles justifies the further conclusion that the ellect produced by the $a$-rays on a metal consists in the direct expulsion of electrons, and not of neutral pairs which afterwards break up. As will be seen later, there is a very close relationship between this metal effect and the ordinary ionization of gases by $\alpha$-rays; and the result just given renders it at least unlikely that neutral pairs are emitted when gases are ionized by $\alpha$-rays as has been sometimes assumed in the case of other ionizing agents.

A further test of the relative importance of the metal and gas effects was made by measuring the current at different gas pressures up to $0.2 \mathrm{~mm}$. The result may be expressed by the linear formula

$$
i=A+B_{T},
$$


where $i$ is the current, $p$ the pressure, and $A$ and $B$ are constants. In the apparatus described, $\mathrm{B} p$ was equal to $\mathrm{A}$ when $p=.068 \mathrm{~mm}$., so that even with a pressure of several thousindths of a millimetre, the gas effect was small in comparison with the metal effect.

The above measurements (which were incidental and somewhat rough) permit an estimate of the number of electrons emitted when one $\alpha$-particle passes through the aluminium foil electrode. The $\alpha$-rays were at a point in their range corresponding to a distance in air from the polonium of 2.07 cm. At this point in the range Geiger's * results show that an $\alpha$-particle produces about 4000 ions per $\mathrm{mm}$. of its path in air at standard pressure. In the present case, the depth of the ionization-chamber was $40 \mathrm{~mm}$.; most of the rays passed through somewhat obliquely and the average distance traversed was about $45 \mathrm{~mm}$. At a pressure of $068 \mathrm{~mm}$. the ions per $\alpha$-particle would be

$$
4000 \frac{45 \times 068}{760}=16 .
$$

Half of these (the positives) reached the electrode and gave an effect equal to that of the electrons which left it. The number of electrons leaving both sides of the foil for each $\alpha$-particle passing through it is thus approximately eight $\dagger$.

The foregoing preliminary experiments having shown that the effects observed in the electroscope were due to the emission of electrons from the surfaces of the metal, the speed of the $x$-particles was varied by interposing sheets of aluminium foil between the polonium and the corer of the exhausted chamber. Foils of two different thicknesses were used; the thinner was $0.64 \times 10^{-4} \mathrm{~cm}$. in thickness and its approximate air-equivalent, according to 'laylor's results, was $0.116 \mathrm{~cm}$. ; the other was $3.2 \times 10^{-4} \mathrm{~cm}$. thick and was equivalent to $0.58 \mathrm{~cm}$. of air ; it happened to be just five times as thick as the first foil.

With the case charged to +40 volts, the current of electrons from the electrode was measured as successive layers of foil were interposed. 'The current increased until five or six of the thin foils bad been added, after which it

* Proc. Roy. Snc. Ixxxii. p. 486 (1909).

+ Hauser, Phys. Zeitsch. xii. p. 4 C6 (1911), whose paper appeared after the completion of these experiments, finds that about 20 electrons are emitted from one side (the emergence side) of an aluminium foil for each a-particle. 


\section{Prof. H. A. Bumstead on Emission of Electrons}

rapidly decreased. Curve I. (fig. 2) shows the result of a series of such measurements made on Jan. 12, 1911. In the

Fig. 2.

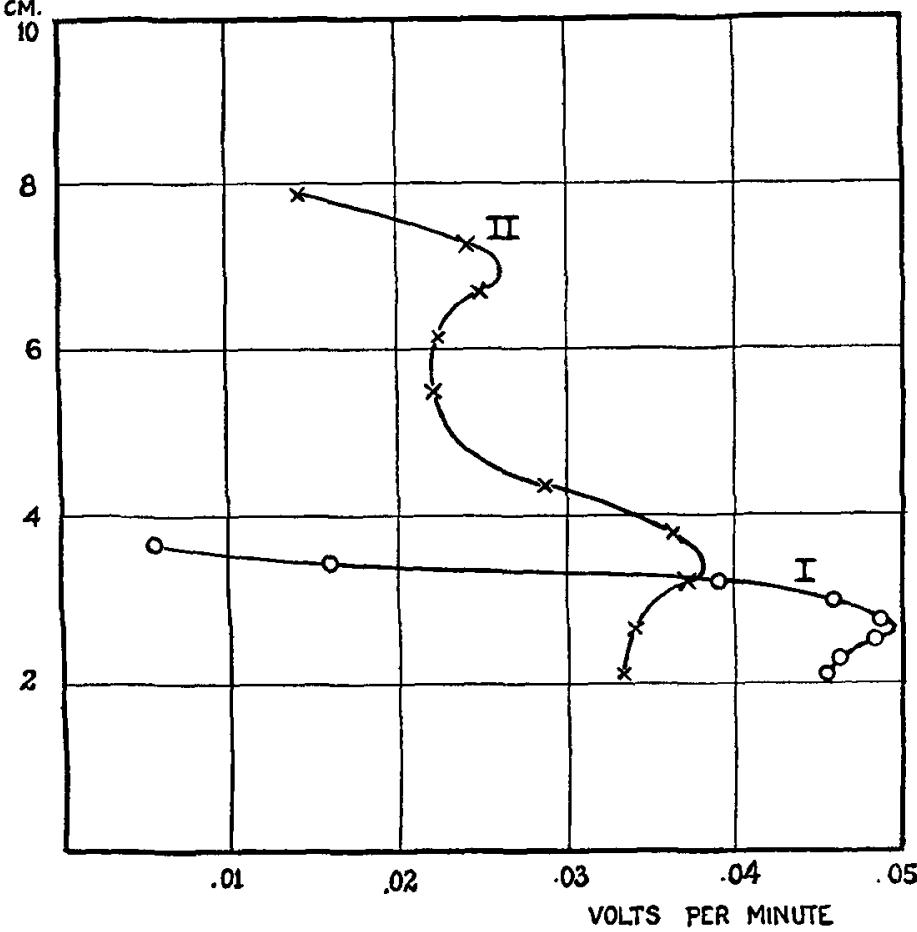

Curve I. Polonitum.

Curve II. Thorium Active Deposit.

figure, the currents in volts per minute are plotted as abscissæ, and the number of layers of foil as ordinates; in order to facilitate comparison with the ionization curve of polonium, however, the scale of ordinates indicates the airequivalents of the foils. Each plotted point is the mean of from three to six separate observations, taken in various orders and with frequent returns to the measurement of the current with no foils, to check the constancy of the electroscope readings. Several repetitions of these measurements gave entirely similar resnlts.

Before entering the case the $\alpha$-rays passed through $0.6 \mathrm{~cm}$. of air and through the thick aluminium foil which covered the holes in the top and whose air-equivalent was $1.47 \mathrm{~cm}$., so that, with this apparatus, only the upper part of the 
polonium curve can be obtained. To obtain $\alpha$-rays of greater range, $I$ used the active deposit from the thorium emanation which emits $a$-rays of two different speeds; the rays from thorium $B$ have a range in air of $5.0 \mathrm{~cm}$, and those from thorium $\mathrm{C}$, of $8.6 \mathrm{~cm}$. An additional advantage is the slow rate of decay of the thorium active deposit which falls to half value in $10 \cdot 6$ hours.

A small quantity ("activity of $2 \cdot 4 \mathrm{mg}$. $\mathrm{RaBr}_{2}$ ") of Professor H:lhn's mesothorium, obtained from Knöfler \& Co. of Berlin, was available. This was placed in a small cylindrical cup of platinum with a hemispherical bottom, and was slightly moistened to increase its emanating power. The top of the cup was closed with a rather thick stopper of ebonite, in the centre of which was a hole through which passed a copper plug of the same dimensions as that on which the polonium had been deposited $(4 \mathrm{~mm}$. in diameter $)$. The lower end of this plug was flush with the bottom of the ebonite stopper which was about halfway between the top and bottom of the cup. By this arrangement, when the cup was charged to +80 volts with respect to the copper plug, most of the lines of force which passed through the emanation fell upon the end of the plug and the greater part of the actire deposit was collected there. After an exposure of 24 hours the accumulated deposit was sufficient to give very good readings in the apparatus described above, though somewhat less than had been obtained with the polonium. As there is an appreciable amount of radium with the mesothorium, it is necessary to wait about two or three hours before beginning measurements, in order to allow the radium active deposit to decay to a small value.

Series of observations were made in the same manner as with the polonium except that the thicker aluminium foil alone was used. On account of the decay of the active deposit it was necessary to complete a series within a reasonable number of hours, and it was desirable to repeat each neasurement several times to guard against possible vagaries of the electroscope. Each reading was corrected in the ustal manner for the decay of the active deposit. Curve II. (fig. 2) shows the result of the series of Mar. 9, 1911, which is typical of other similar series. The two "knees" are distinctly shown and their position is in excellent agreement with the ionization curve in air given by Haln*.

It appears from these experiments that (as was anticipated) the secondary $\delta$-radiation from the aluminium varies with 


\section{Prof. H. A. Bumstead on Emission of Electrons}

the speed of the $\alpha$-rays prolucing it in a manner entirely analogous to the variation in the gaseous ionization under like conditions. But the possibility of an error in this conclusion here suggests itself. Wheu the $\alpha$-particle is not near the end of its range it passes through the thin aluminium electrode and the latter receives its positive charge solely on account of the electrons emitted by it. Near the end of the range, however, some of the $a$-particles (those entering most obliquely) will stop in the foil, and it is possible that the observed increase in the pasitive charge acquired by the electrode is due to the positive charges on these $\alpha$-particles and not to any true increase in the $\delta$-radiation. It is easy to test this by charging the case negatively and measuring the negative charge received by the electrode from the electrons emitted by the case, for uniler these circunstances the stoppage of $\alpha$-particles by the electrode would decrease, instead of increasing, the effoct. Unfortunaiely when this was tried a decisive result was not obtained. The current observed in the electroscope remained nearly constant while several foils were interposed and then fell off more gradually than with the positive charge on the case. As will be shown in the following pages, however, this was not due to the cause suggested above, but was in all probability the result of the construction of the chamber. As has heen pointed out, many of the $\alpha$-rays must have struck the sides of the holes in the top at various angles up to grazing incidence. Thus the electrons emitted from the case were not all produced by particles moving with approximately the same speed, but by particles whose velocities varied considerably. Hence the effect was somewhat analogous to ionization curves obtained when the pencil of rays is not limited to a small angle by a "Bragg screen."

However, it was necessary to investigate the matter further. As a more intense source of radiation was desirable, Professor Boltwood was good enough to attempt the preparation of a much stronger deposit of poloninm. By a special method he succeeded in depositing upon a $4 \mathrm{~mm}$. plug as much polonium as would be in equilibrium with about $0.6 \mathrm{mg}$. of radium, and yet having so little foreign material with it that it appeared as a mere discoloration upon the copper. With this preparation, the difficulties of the experiment were greatly lessened; an electrometer could be used instead of the electroscope and much larger and steadier readings could be obtrined.

In order to avoid the difficulties mentioned above, which prevented satisfactory readings when a negative potential 
by Metals under the Influence of Alpha Rays.

was put on the case, the experimental arrangements were altered.

Fig. 3.

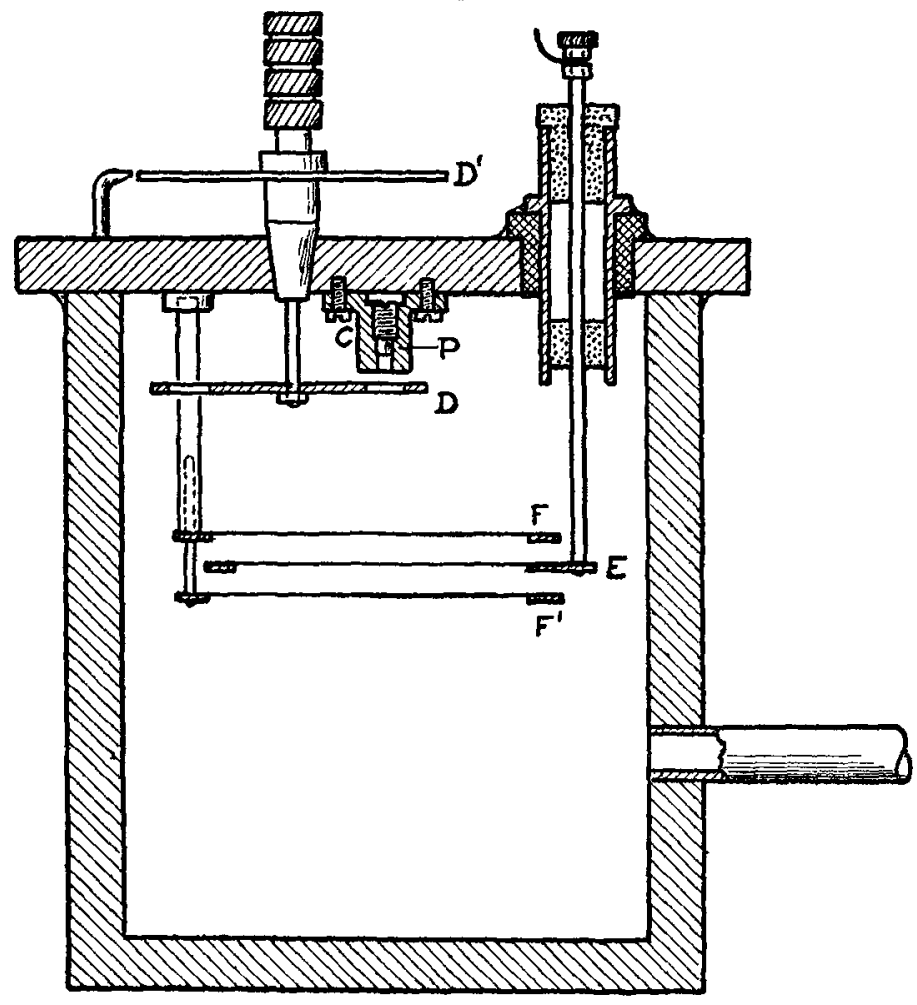

CENTISETERS

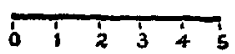

The polonium-coated plug $\mathrm{P}$ (fig. 3) is placed within the evacuated chamber; it is surrounded by a brass cylinder $C$, whose opening limits the cone of rays so that they fall within the ring $\mathbf{E}$ which supports the aluminium-leaf electrode. Two other rings $\mathrm{F}$ and $\mathrm{F}^{\prime}$ above and below the electrode at a distance of $7 \mathrm{~mm}$. are also covered with the aluminium leaf; they are in metallic connexion with each other and with the case. The brass disk $D$ is divided into six equal sectors; one of these is left blank so that the rays may be stopped, while the five others have holes through them $1.3 \mathrm{~cm}$. in diameter. These five holes are covered respectively with 2 , Phil. Mag. S. 6. Vol. 22. No. 132. Dec. 1911. 3 P 
$3,4,5$, and 6 layers of the thicker aluminium foil whose airequivalent is $\cdot 58 \mathrm{~cm}$. The disk can be rotated about its axis which passes throngh the cover-plate with a cone bearing, made tight by rubber stopcock grease. A dial, $\mathrm{D}^{\prime}$, enables one to set the disk so that the different layers of foil are interposed, or the rays stopped altogether by the blank sector. The electrode is insulated from the case by amber, guard-tube, and ebonite, and the joints made tight by sealingwax; it was connected with a Dolezalek electrometer which, with 80 volts on the neelle, had a sensitiveness of about $650 \mathrm{~mm}$. divisions per volt. It was necessary to reduce somewhat the current-sensitiveness of the instrument; for this purpose a small mica condenser of about $150 \mathrm{~cm}$. capacity was put in parallel with the electrometer.

With a positive potential on the case, the saturation current was reached with 40 volts; and when the brass sector was interposed in the path of the rays the current fell to a negligible value. On the other hand, it was impossible to approach saturation with a negative potential on the case, even at -320 volts; the negative current when the rays were stopped by the disk was always large (20-40 per cent. of the total) and increased with the negative potential on the case. This part of the current was due to the electrons set free between the polonium and the disk; by subtracting this from the currents obtained with the foils interposed it was possible to eliminate this disturbing portion of the negative current. What was left consisted of the electrons from the two foils on the rings $F, F^{\prime}$, and from the surfaces of the disk-foils furthest from the polonium.

With this apparatus, practically identical results were obtained whether the case was charged positively or negatively; that is to say, whether the electrode emitted electrons or received those given off by the othor aluminium foils. In the following table (p. 919), the results of various series of measurements are given. In order to facilitate comparison the currents are reduced to the same scale, that obtained with 2 foils (the smallest number used) being taken as 100 in each case.

These results leave no doubt, I think, that the increase in the secondary $\delta$-radiation is real, and is not due to the charge on the $\alpha$-particles themselves. The descrepancy between the positive and negative currents when six foils are interposed is easily explained. With a negative charge many of the electrons come from the foil on the disk $\mathrm{D}$; with a positive charge they all come from the electrode $\mathrm{E}$, and to reach this the $\alpha$-rays must penetrate the foil $F$ (airequivalent $=0.116 \mathrm{~cm}$.). With 6 foils interposed we are in 
by Metals under the Inflience of Alpha Rays.

TABLE I.

\begin{tabular}{|c|c|c|c|c|c|c|c|}
\hline \multirow{2}{*}{\multicolumn{2}{|c|}{ Date. }} & \multirow{2}{*}{$\begin{array}{c}\text { Volts } \\
\text { on } \\
\text { Case. }\end{array}$} & \multicolumn{5}{|c|}{ Number of Foils. } \\
\hline & & & 2. & 3. & 4. & 5. & 6. \\
\hline May 23 & & +160 & 100 & $107 \cdot 2$ & $118 \cdot 5$ & 107 & 39 \\
\hline , & ...... & -160 & 100 & $10 t$ & $118 \cdot 2$ & 107 & 54 \\
\hline May 27 & $\ldots \ldots$ & +80 & 100 & $104 \div 5$ & 1162 & $106 \cdot 8$ & $38 \cdot 7$ \\
\hline$"$ & 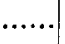 & -80 & 100 & $104 \cdot 6$ & 119 & $108 \cdot 6$ & $55 \cdot 5$ \\
\hline June 9 & . & +80 & 100 & 106 & 118 & 109 & $39 \cdot 5$ \\
\hline , & ...... & -80 & 100 & $101 \cdot 5$ & 119 & 110 & $51 \cdot 8$ \\
\hline
\end{tabular}

the nearly horizontal "top" of the curve, and a small difference in the range makes a considerable difference in the effect *.

In order to test the effect with another metal, three gold leaves were put upon the rings $E, F$, and $F^{\prime}$ instead of aluminium. These leaves were $\cdot 09 \times 10^{-4} \mathrm{~cm}$. thick and had an air-equivalent of approximately $0.05 \mathrm{~cm}$. (about balf of that of the aluminium leaf). The emission from the gold

* An effect probably due to this increased emission of electrons with diminishing speed of the a-particles was observed by Aschkinass (Ann. d. Phys. xxvii. p. 377 (1908)). He was measuring the charge of the aparticles after passing through various thicknesses of aluminium, and had a transverse magnetic field to curl up the $\delta$-rays. The a-rays passed through an aluminium window into a separate chamber and fell upen a copper plate. Even without a magnetic field the plate acquired a positive charge; when a small thickness of aluminium was in the path of the rays, the magnetic field increased this positive charge, but only slightly (evidently the number of electrons enitted by the window and falling upon the plate was in excess of the number emitted by the plate itself but this excess was not enough to neutralize the charge carried by the a-rays). When the a-rays had to pass through a thicher layer of aluminium, the application of the nugnetic field diminished the positive clarges acquired by the plate (in this case, the electrons emitted by the plate appear to be in excess of those received from the window). The author draws the conclusion that "with diminishing speed of the primary aparticles, it appears that the intensity of the secondary radiacion inrreases, at first slowly, and finally considerably." It does not appear that the conclusion is altonether justified by the experiment; the $\delta$-radiation from the window seems to have been left ant of consideration; the most that can be concluded is that there is a differential effect as between copper and aluminium.

Another effect which is doubtless due to the same cause was observed by Duane (C.R. clxvi. p. $1088(1908))$. He found that the secondary radiation ceases a little less abruptly at the end of the range than the charge on the a-particles. As he used an unlimited beam of rays, this result may well have been due to the increased emission of electrons near the end of the range. 


\section{0}

\section{Prof. H. A. Bumstead on Emission of Electrons}

electrode was about 13 per cent. less than from the aluminium but the variation with the speed of the $\alpha$-rays was very nearly thrs same. In the following table are given the averages for all the experiments with both motals (with positive potential on the case); the currents with 2 foils are called 100 as before. Included in the table are two series of ionization measurements. These were made by removing the foil from the electrode $\mathrm{E}$, admitting a small quantity of air (pressure $.032 \mathrm{~mm}$.), and charging the case positively. The first of the two ionization measurements is with the aluminium leaf on $\mathrm{F}$ and $\mathrm{F}^{\prime}$, the second with the gold leaf.

TABLE II.

\begin{tabular}{|c|c|c|c|c|c|}
\hline No. of Foils. & 2. & 3. & 4. & 5. & 6. \\
\hline Al ................... & 100 & $105 \cdot 2$ & $117 \cdot 6$ & $107 \cdot 3$ & $39 \cdot 1$ \\
Gold ................. & 100 & $105 \cdot 6$ & $118 \cdot 2$ & $115 \cdot 6$ & $72 \cdot 2$ \\
Air (b) .............. & 100 & $110-5$ & 134 & 145 & 573 \\
Air (2) ............... & 100 & 110 & 130 & 143 & 96.5 \\
\hline
\end{tabular}

As will be seen, the course of the series with the two metals is nearly identical; the differences in the last column are to be attributed to the greater stopping-power of the aluminium leaf ; it appears also in the two ionization experiments with

Fig. 4.

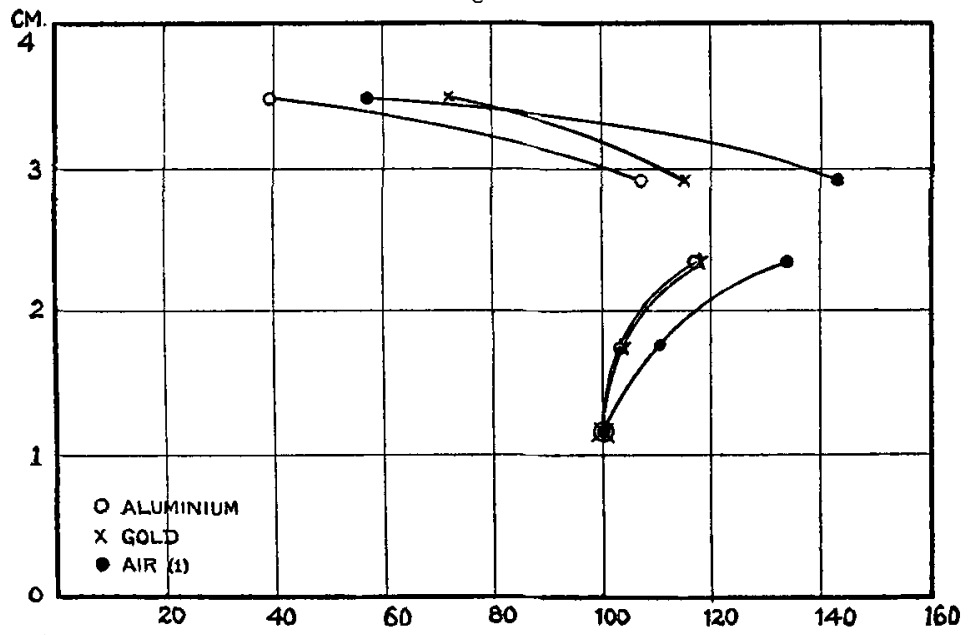

the two metals on the ring F. Fig. 3 gives a graphical reprsentation of these results; it is to be remembered, 
however, that the ordinates of the different curves are not exactly adjusted to each other, on account of the differences just mentioned. It is indeed impossible to make satisfactory correction for these differences without knowing the relative values of the "incidence" and "emergence" $\delta$-radiation; for, between the generation of the two, the $\alpha$-rays pass through the leaf on the electrode, in the one case aluminium, in the other case gold. It is plain, however, that this correction (if it conld be made) would bring closer together the two curves in their decreasing portions, while it would not much affect their increasing portions where they are already in close agreement.

The results of Taylor, mentioned at the beginning of this paper, would lead us to expect that the metal curves would lie to the left of the air-curve and have a less pronounced knee, as appears to be the case. But they give equal grounds for anticipating that the gold curve should be to the left of that obtained with aluminium, and this is not confirmed by the experiments. Quite apart from these somewhat hypothetical considerations it does not appear probable that two metals which differ so much in atomic weight and in other properties should give effects so nearly identical ; the ionization curves in different gases are markedly different even when the gases differ much less from each other than gold and aluminium. The close similarity observed with the two metals gives rise to the suspicion that the electrons we have been measuring are emitted, not from the metals themselves, but perhaps from a layer of adsorbed gas which is the same in both cases. I have not yet had an opportunity to test this possibility, or to obtain the "ionization curves" of other metals, but I hope to do so shortly. The observation of Aschkinass (p. 919, footnote) seems to indicate that copper and aluminium would not give identical results.

\section{Conclusions.}

1. The emission of electrons by aluminium and gold foils $u n$ der the influence of $\alpha$-rays (secondary $\delta$-rays) varies with the speed of the a-rays in a manner entirely analogous to the variation in the gaseous ionization produced by $a$-rays. T'he emission at first increases and then rapidly decreases as the $\alpha$-rays near the end of their range, and the curves obtained show all the characteristics of the ionization curves in gases first obtained by Bragg.

2. The curves lie within (to the left of) the corresponding curves for gases and have a less conspicuous "knee." So 
far they are in agreement with the known results on the retardation of a-rays by melals, and with the hypothesis that the loss of energy by the $\alpha$-particles is due to an ionization of the metallic molecules. But the close similarity in the behaviour of gold and aluminium is not in accordance with this view.

3. In view of the dissimilarity in the ionization curves of different gases, the agreement in the curves obtained for aluminium and gold is unexpected, and leads to the suspicion that the observed effects may not be due to the metals themselves, but perhaps to a layer of adsorbed gas in both cases. A further investigation of this question will be undertaken shortly.

Sloane Iaboratory,

Yale University.

August, 1911.

LXXXVIII. On a Relation between the Atomic Iolumes and the Spectra of Elements. By R. Rossi, M.Sc.*

$\mathrm{F}$ the recent theories explaining the possible origin of series of lines in spectra, the one which most seems to agree with experimental facts is due to Ritz $\dagger$.

Ritz considers an electron vibrating in a magnetic field of strength $\mathrm{H}$, the frequency of vibration being

$$
\nu=\frac{e}{m c} H,
$$

where $\frac{e}{m c}$ is the ratio of the charge to the mass of the electron in electromagnetic units. The field $\mathbf{H}$ can be ascribed to elementary molecular magnets in a line, the electron being on their axis, at a distance $r$ from the nearest pole. The field is then expressed by

$$
\mathrm{H}= \pm \mu\left(\frac{1}{r^{2}}-\frac{1}{(r+l)^{2}}\right)
$$

$\pm \mu$ being the magnetic charge on each pole, $l$ the length of the magnet, supposed to be made up by these elementary magnets. If $l=n s$, where $n$ is an integer and $s$ the length of an elementary magnet, and if we write $r=a s$ we get

* Communicated by Prof, E. Rutherford, F.R.S.

† Magnetische Atomfelder und Serienspektren,'Ann. der Physiz, xxv. p. 660 (1908). 